\title{
Effect of antibiotic treatment on inflammatory markers and lung function in cystic fibrosis patients with Pseudomonas cepacia
}

\author{
D Peckham, S Crouch, H Humphreys, B Lobo, A Tse, A J Knox
}

\begin{abstract}
Background - The acquisition of Pseudomonas cepacia in patients with cystic fibrosis is associated with increasing deterioration in lung function and more frequent hospital admissions. Pseudomonas cepacia is usually resistant to several antibiotics in vitro, but the response of patients colonised with the organism has not been extensively studied in vivo.

Methods - A three month prospective study was performed to investigate the response of $14 \mathrm{Ps}$ cepacia positive patients and $10 \mathrm{Ps}$ cepacia negative patients to a two week course of intravenous antibiotics. All those who were $P$ s cepacia negative and six of the $14 P s$ cepacia positive patients had $P s$ aeruginosa in their sputum which was sensitive to the prescribed therapy. The inflammatory markers Creactive protein, white blood cell count, serum lactoferrin, neutrophil elastase $/ \alpha_{1}-$ antitrypsin complex, and tumour necrosis factor alpha were measured at the start and end of each antibiotic course.
\end{abstract}

Results - The median (range) \% improvement in baseline FEV 1 and FVC following treatment in the group as a whole was $15.2 \%(-23.5 \%$ to $156.3 \%)$ and $23.9 \%$ $(-36 \cdot 8 \%$ to $232 \cdot 7 \%)$ respectively. There was no statistical difference in improvement in lung function, body weight, or inflammatory markers between individuals who were $P$ s cepacia positive and those who were Ps cepacia negative.

Conclusions - Patients who are Ps cepacia positive appear to respond as well to intravenous antibiotics as those who are $P s$ cepacia negative, despite having lower lung function and a bacterium in their sputum which is resistant in vitro to the antibiotics used.

(Thorax 1994;49:803-807)

$S$ Crouch

B Lobo

A J Knox

Department of Microbiology, Queens Medical Centre, University Hospital University Hospital, H Humphreys

Reprint requests to: Dr D Peckham.

Received 7 February 1994 Returned to authors 5 April 1994

Revised version received 20 April 1994

Accepted for publication

26 April 1994

In the UK the incidence and prevalence of Pseudomonas cepacia among patients with cystic fibrosis has significantly increased over the past few years. ${ }^{1-3}$ This can partly be explained by improvement in microbiological isolation techniques and by an increase in both social and hospital contacts among patients with cystic fibrosis. ${ }^{2}$ Despite the increased evidence for patient to patient transmission, it remains unclear whether Ps cepacia is a cause of, or marker of, disease severity. cepacia rapid and unexpected lung deterioration develops despite intensive antibiotic treatment. The isolation of Ps cepacia from blood cultures accompanied by clinical evidence of systemic sepsis provides evidence of a possible pathogenic role for this organism. ${ }^{145}$ In most patients, however, a gradual decline in lung function occurs following the isolation of the organism. ${ }^{6}$

Pseudomonas cepacia is resistant to most antipseudomonal antibiotics in vitro. ${ }^{7}$ Our clinical impression is nevertheless that patients respond clinically to these antibiotics. Markers such as serum levels of neutrophil elastase $/ \alpha_{1}-$ antitrypsin complex, lactoferrin, tumour necrosis factor alpha ( $T N F \alpha)$, C-reactive protein, and white blood cell count have been shown previously to reflect the inflammatory process in patients with cystic fibrosis and are reduced following effective antipseudomonal treatment in patients colonised with $P$ s aeruginosa.$^{8-10} \mathrm{It}$ is not known, however, whether similar changes are seen after treatment in patients colonised with Ps cepacia. We have therefore prospectively studied the effectiveness of intravenous antibiotic therapy in a group of adult patients with cystic fibrosis, with and without Ps cepacia, measuring treatment response as change in inflammatory markers, lung function, and body weight.

\section{Methods}

STUDY DESIGN

This was a prospective study which included all patients who required two weeks of intravenous antibiotics for infective exacerbations of cystic fibrosis over a three month period at Nottingham City Hospital. Patients were assessed both before and at the end of the two week course of antibiotics with measurements of body weight, lung functions, and venous blood samples for measurements of inflammatory markers.

\section{PATIENTS}

In a small proportion of patients with $P S$
Twenty four adult patients were studied, 10 of whom were colonised with Ps aeruginosa without Ps cepacia (Ps cepacia negative) and 14 of without $P$ s aeruginosa ( $P$ s cepacia positive). Clinical details are outlined in table 1. All patients had been chronically infected with $P S$ aeruginosa for more than two years. Of the patients who were $P s$ cepacia positive, this bacterium had been isolated from one patient three weeks before antibiotic therapy while the remaining 13 had repeatedly been positive for whom were colonised with Ps cepacia, with or 
Table 1 Clinical details of 24 adult patients with cystic fibrosis

\begin{tabular}{|c|c|c|c|}
\hline & $\begin{array}{l}\text { Ps cepacia positive } \\
(n=14)\end{array}$ & $\begin{array}{l}\text { Ps cepacia negative } \\
(n=10)\end{array}$ & $p$ \\
\hline $\begin{array}{l}\text { Mean age (years) } \\
\text { M:F } \\
\text { Schwachman score } \\
\text { Chrispin-Norman score } \\
\text { Post-treatment FEV }(1 / \mathrm{s}) \\
\% \text { predicted FEV } \\
\text { Post-treatment FVC (1) } \\
\text { \% predicted FVC }\end{array}$ & $\begin{array}{l}22 \cdot 8 \\
10: 4 \\
45(25-70) \\
20(16-32) \\
1 \cdot 17(0 \cdot 58-2 \cdot 21) \\
31(14-64) \\
1 \cdot 75(0 \cdot 76-3 \cdot 5) \\
46(16-70)\end{array}$ & $\begin{array}{l}22 \cdot 2 \\
6: 4 \\
65(30-80) \\
20(9-32) \\
1 \cdot 66(0 \cdot 71-4 \cdot 93) \\
48(17-88) \\
2 \cdot 73(1 \cdot 66-5 \cdot 64) \\
65(35-79)\end{array}$ & $\begin{aligned}<0.05 \\
>0.05 \\
0.05 \\
>0.05 \\
<0.001 \\
<0.05\end{aligned}$ \\
\hline
\end{tabular}

Values are median (range). received an aminoglycoside (gentamicin or tobramycin) with $\mathbf{5} \mathbf{g}$ three times daily azlocillin (one patient), or $2 \mathrm{~g}$ three times daily ceftazidime (seven patients), $2 \mathrm{~g}$ three times daily aztreonam (one patient) or $1 \mathrm{~g}$ three times daily imipenem alone (one patient). Patients who were $P$ s cepacia positive received a combination of an aminoglycoside with either ceftazidime (eight patients), azlocillin (five patients), or aztreonam (one patient) at the identical doses to patients who were Ps cepacia negative. Antibiotic regimens were selected according to sensitivity results of both $P$ s aeruginosa and $P s$ cepacia, and in patients who were Ps cepacia positive combination therapy was used. The choice of antibiotics was arbitrary when a multiresistant strain of Ps cepacia was isolated in the absence of Ps aeruginosa. At the start of treatment all 10 isolates of $P$ s aeruginosa among patients who were Ps cepacia negative and five isolates of Ps aeruginosa from patients who were Ps cepacia positive were fully sensitive to the antibiotics used. One patient who was Ps cepacia positive grew a Ps aeruginosa isolate which proved to be sensitive to tobramycin alone. Of the 14 patients who were Ps cepacia positive 12 had a multiresistant strain of Ps cepacia in their sputum while the isolates from two patients were sensitive to ceftazidime alone. Two patients in the Ps cepacia positive group and one in the Ps cepacia negative group received either high dose oral amoxicillin ( $3 \mathrm{~g}$ twice daily) or intravenous cefuroxime ( $1.5 \mathrm{~g}$ three times daily) to treat additional $H$ influenzae (table 2), while one patient in each group was treated with oral flucloxacillin ( $1 \mathrm{~g}$ four times daily) for additional Staphylococcus aureus infection. Serum aminoglycoside levels were measured around the fourth dose and again on the third or fourth day thereafter, with dose adjustment as appropriate to maintain a serum peak concentration of 7-10 mg/l. Five patients who were Ps cepacia negative and five who were $P$ s cepacia positive were on long term nebulised antibiotic therapy which was discontinued during the study period. Of the patients who were Ps cepacia negative two were on colomycin (1 megaunit twice daily), two on gentamicin ( $80 \mathrm{mg}$ twice daily) and one on tobramycin ( $80 \mathrm{mg}$ twice daily), while amongst patients who were $P s$ cepacia positive four were on colomycin (1 megaunit twice daily) and one was on gentamicin (80 mg twice daily).

mycin, ceftazidime, azlocillin, ciprofloxacin, aztreonam, imipenem, and polymyxin B was carried out using the disc diffusion method. ${ }^{11}$

ANTIBIOTIC TREATMENT

All patients who were Ps cepacia negative

Table 2 Organisms isolated from sputum of patients before treatment with intravenous antibiotics

\begin{tabular}{ll}
\hline & Frequency \\
\hline Ps cepacia negative & \\
Ps aeruginosa alone & 8 \\
Staph aureus and Ps aeruginosa & 1 \\
H influenzae and Ps aeruginosa & 1 \\
Ps cepacia positive & 6 \\
Ps cepacia alone & 6 \\
Ps cepacia and Ps aeruginosa & 1 \\
Ps cepacia, Staph aureus and $H$ influenzae & 1 \\
H influenzae and Ps cepacia & \\
\hline
\end{tabular}

\section{INFLAMMATORY MARKERS}

Full blood count with differential counts was measured by conventional automated analysis, C-reactive protein by a nephelometry method, ${ }^{10}$ and other inflammatory markers by enzyme linked immunosorbent assay (ELISA) following serum storage at $-70^{\circ} \mathrm{C}$. The lactoferrin ELISA used ${ }^{12}$ had a lower detection limit of $0.005 \mathrm{nmol} / 1$. Immunoreactive TNF was measured according to a previously described method $^{13}$ with a lower detection limit of $6.25 \mathrm{pg} / \mathrm{ml}$. Elastase $/ \alpha_{1}$-antitrypsin was measured using a modification of a previously described method $^{14}$ where the streptavidin horseradish peroxidase step was replaced with 
Table 3 Median (range) results for inflammatory markers before and after treatment in the combined group of 24 adult patients with cystic fibrosis

\begin{tabular}{lccc}
\hline Inflammatory markers & Before treatment & After treatment & $p$ \\
\hline White cell count $\left(\times 10^{9} / 1\right)$ & $10 \cdot 9(2 \cdot 4-21 \cdot 5)$ & $8 \cdot 7(2 \cdot 0-18 \cdot 3)$ & 0.005 \\
C-reactive protein $(\mathrm{mg} / \mathrm{l})$ & $29(<11-169)$ & $<11 \mathrm{mg} / 1(<11-130)$ & 0.001 \\
Lactoferrin $(\mathrm{nmol} / \mathrm{l})$ & $6 \cdot 97(3 \cdot 87-8.99)$ & $4 \cdot 87(3 \cdot 29-7 \cdot 87)$ & 0.02 \\
Tumour necrosis factor $(\mathrm{pg} / \mathrm{ml})$ & $42 \cdot 25(0-1055)$ & $27 \cdot 2(0-604 \cdot 5)$ & $>0.05$ \\
Elastase $/ \alpha_{1}$-antitrypsin complex $(\mathrm{ng} / \mathrm{ml})$ & $728(277-1541)$ & $407 \cdot 5(54-842)$ & $<0.001$ \\
\hline
\end{tabular}

an alkaline phosphatase conjugate to streptavidin. An AMPAK amplification kit (Dako) was used to increase the sensitivity of the assay allowing detection of the complex to $10 \mathrm{ng} / \mathrm{ml}$ in the serum.

\section{DATA ANALYSIS}

Because the data were not normally distributed the results were expressed as medians and ranges. Changes in weight, lung function, and inflammatory markers were analysed in patients who were Ps cepacia positive, those who were Ps cepacia negative, and both groups combined using Wilcoxon and Mann-Whitney tests for paired and unpaired data respectively (Microsoft Corporation, Redmond, USA). Subgroup analysis comparing the same variables in the $P s$ cepacia positive group (six patients $P s$ aeruginosa positive, six patients $P s$ aeruginosa negative) was also carried out. A p value $<0.05$ was regarded as statistically significant.

\section{Results}

Patients who were Ps cepacia positive had significantly lower median $\mathrm{FEV}_{1}, \mathrm{FVC}$, and Schwachman scores after treatment than patients who were Ps cepacia negative, although Chrispin-Norman scores were similar (table 1).

\section{SPIROMETRY}

When patients who were $P$ s cepacia positive and Ps cepacia negative were combined lung function improved significantly following antibiotic treatment from a median (range) $\%$ predicted $\mathrm{FEV}_{1}$ and FVC before therapy of $28.5 \%$ (11$67 \%)$ and $38 \%(9.4-80 \%)$ respectively to a median (range) $\mathrm{FEV}_{1}$ of $34.5 \%$ (14-88\%, $\mathrm{p}<0.05)$ and FVC of $53 \%(16-79 \%, \mathrm{p}<0.05)$. The median \% improvement of $\mathrm{FEV}_{1}$ and FVC following antibiotics was $15 \cdot 23 \%(-23.46 \%$ to $156 \cdot 25 \%)$ and $23.99 \%(-36.8 \%$ to $232.7 \%)$ respectively.

There was no difference in \% improvement of $\mathrm{FEV}_{1}$ and $\mathrm{FVC}$ before and after treatment when comparing patients who were Ps cepacia positive and negative. The median (range) $\%$ improvement of $\mathrm{FEV}_{1}$ and FVC from baseline in patients who were Ps cepacia positive was $19.49 \%(-23.46 \%$ to $156.25 \%, \mathrm{p}>0.05)$ and $23.35 \%(-36.8 \%$ to $232.65 \%, \mathrm{p}<0.05)$ re- spectively, and $8.075 \%(-7 \cdot 73 \%$ to $99.6 \%$, $\mathrm{p}>0.05)$ and $23.99 \%(-3.9 \%$ to $145.9 \%$, $\mathrm{p}>0.05)$ in patients who were Ps cepacia negative.

There was no difference between the $\%$ improvement in both $\mathrm{FEV}_{1}$ and FVC among the six patients who were $P s$ aeruginosa and $P s$ cepacia positive, and the six patients who were Ps cepacia positive but Ps aeruginosa negative.

\section{WEIGHT}

The median (range) weight of all patients was $53 \cdot 2(39 \cdot 1-72 \cdot 5) \mathrm{kg}$ before treatment and 54.2 $(40 \cdot 6-76 \cdot 6) \mathrm{kg}(\mathrm{p}=0.001)$ after treatment. The median improvement in weight was $0.5(-1.2$ to $4 \cdot 7) \mathrm{kg}$.

The median weight of patients who were $P s$ cepacia positive was $53 \cdot 2(39 \cdot 1-66 \cdot 3) \mathrm{kg}$ before and $54 \cdot 1(40 \cdot 6-68 \cdot 8) \mathrm{kg}$ after treatment whereas in patients who were Ps cepacia negative the corresponding results were $53.4(44 \cdot 6-72 \cdot 5) \mathrm{kg}$ and $55.3(45-76 \cdot 6) \mathrm{kg}$ respectively. The difference in change in weight between patients who were Ps cepacia positive and negative was not significant. There was no difference in the change in weight during treatment when the six patients with Ps aeruginosa and Ps cepacia were compared with the six patients with Ps cepacia alone. Seven of the patients who were Ps cepacia positive were on long term nasogastric feeding compared with only two of the patients who were Ps cepacia negative.

\section{INFLAMMATORY MARKERS}

The results before and after treatment for the combined group are outlined in table 3. There was a significant fall in white blood cell count and serum levels of C-reactive protein, lactoferrin and $\alpha_{1}$-antitrypsin following treatment for the combined group. No differences were detected in the parameters studied between patients who were Ps cepacia positive and those who were Ps cepacia negative or between the two Ps cepacia subgroups (six Ps aeruginosa positive, six Ps aeruginosa negative). No significant difference was seen in the pretreatment, post-treatment, or in the change in any of the measured parameters. The median changes following treatment in the two groups are outlined in table 4.

Table 4 Median (range) change in inflammatory markers following intravenous antibiotic therapy in 14 patients who were Ps cepacia positive and 10 patients who were Ps cepacia negative

\begin{tabular}{|c|c|c|c|}
\hline $\begin{array}{l}\text { Change in inflammatory } \\
\text { markers following treatment }\end{array}$ & Ps cepacia positive & Ps cepacia negative & $p$ \\
\hline $\begin{array}{l}\text { White cell count }\left(\times 10^{9} / \mathrm{l}\right) \\
\text { C-reactive protein }(\mathrm{mg} / \mathrm{l}) \\
\text { Lactoferin }(\mathrm{nmol} / \mathrm{l}) \\
\text { Tumour necrosis factor }(\mathrm{pg} / \mathrm{ml}) \\
\text { Elastase } / \alpha_{1} \text {-antitrypsin complex }(\mathrm{ng} / \mathrm{ml})\end{array}$ & $\begin{array}{l}-1 \cdot 1(2.9 \text { to }-9 \cdot 2) \\
-32(5 \text { to }-144) \\
-0.03(1.93 \text { to }-0.56) \\
-38.75(53 \text { to }-235) \\
-350(168 \text { to }-752)\end{array}$ & $\begin{array}{l}-1.6(1.2 \text { to }-8.0) \\
-14(21 \text { to }-169) \\
-0.12(0.80 \text { to }-0.56) \\
0.2(196.6 \text { to }-450.5) \\
-407(100 \text { to }-836)\end{array}$ & $\begin{array}{l}>0.5 \\
>0.5 \\
>0.5 \\
>0.5 \\
>0.5\end{array}$ \\
\hline
\end{tabular}
The $\mathrm{p}$ value shown is for the difference in the change in each variable between patients who were $P$ s cepacia positive and those who
were $P$ s cepacia negative. 
When serum lactoferrin levels are corrected for the number of circulating neutrophils the median (range) for the 24 patients before treatment was $0.885(0.503-1.479) \mathrm{nmol} / 10^{6}$ neutrophils and $0.947(0.368-2.636) \mathrm{nmol} / 10^{6}$ neutrophils following treatment $(p>0.05)$. There were no significant differences between corrected values of serum lactoferrin and TNF levels before and after treatment when patients who were Ps cepacia positive and negative were compared $(p>0.05)$.

\section{Discussion}

Pseudomonas cepacia has been isolated with increasing frequency in specialist centres within the UK. ${ }^{12}$ Isolation of Ps cepacia from patients with cystic fibrosis is associated with poor lung function, increasing age, recent hospitalisation, and close hospital or social contact with other patients who are Ps cepacia positive and siblings. ${ }^{15}$ Despite some evidence to suggest that colonisation with $P s$ cepacia heralds a poorer prognosis, it is unclear whether this is because the organism is pathogenic or because it is a marker for increased disease severity due to other factors..$^{15}$ Pseudomonas cepacia is nonpathogenic in healthy individuals and in animal models it has been found to be relatively avirulent compared with Ps aeruginosa.$^{1617}$ It is possible that $P$ s cepacia acts synergistically with other bacteria to exacerbate chest disease in cystic fibrosis.

In this study we have investigated the effect of intravenous antipseudomonal antibiotic treatment in patients with Ps cepacia infection and have compared this with patients colonised by $P$ s aeruginosa. Several parameters were used to assess response including lung function and various inflammatory markers. In our group of 24 patients studied prospectively we found that lung function and Schwachman scores were lower in patients colonised with Ps cepacia than in those with Ps aeruginosa alone. This is consistent with the results of other studies and suggests an association between colonisation with Ps cepacia and poor clinical status. ${ }^{418} \mathrm{De}$ spite the fact that patients who are Ps cepacia positive had worse lung function and Schwachman scores, antibiotic treatment was equally effective in improving lung function and weight in both groups. Both these parameters improved significantly over the two weeks of treatment in both groups of patients and was similar to that reported in previous studies of patients colonised with Ps aeruginosa. ${ }^{81920}$ The fact that weight improved equally in patients who were $P s$ cepacia positive despite their generally poorer clinical status may partially reflect the fact that more of them were on nasogastric nutritional supplementation.

Several inflammatory markers were measured including white blood cell count and serum levels of C-reactive protein, lactoferrin, neutrophil elastase $/ \alpha_{1}$-antitrypsin complex, and TNF. These have all been shown previously to reflect the inflammatory process in patients with cystic fibrosis. Previous studies of patients colonised with Ps aeruginosa have shown that values of these markers fall following treatment with intravenous antipseudomonal antibiotics. ${ }^{8-10}$

The inflammatory markers elastase $/ \alpha_{1}$-antitrypsin, lactoferrin, and C-reactive protein fell in response to intravenous antibiotic therapy in both patients who were $P$ s cepacia positive and those who were Ps cepacia negative. The changes seen were similar to those found previously in studies of patients colonised with $P s$ aeruginosa. ${ }^{810}$ No significant change in TNF levels occurred following antibiotic therapy in either group, but many patients had undetectable levels of TNF both before and after treatment. Previous studies have expressed lactoferrin levels as absolute values. When we did the same we found a significant reduction in lactoferrin levels with antibiotic treatment. The sole source of lactoferrin is the neutrophil, however, and neutrophil values also fell. ${ }^{2122}$ When the lactoferrin level was adjusted for the neutrophil count no significant change was seen. This suggests that the fall in lactoferrin levels is largely due to the fall in neutrophil count. As with the lung function results, there was no significant difference in improvement in any of the inflammatory markers between patients who were $P$ s cepacia positive and those who were Ps cepacia negative.

The good clinical response to intravenous antibiotic therapy among patients who were $P s$ cepacia positive is surprising in the light of the in vitro sensitivity pattern seen with Ps cepacia. The organism is resistant to most commonly used antipseudomonal agents, ${ }^{7}$ but combinations of antibiotics - for example, aminoglycosides such as gentamicin and a $\beta$-lactam agent such as azlocillin - may, however, inhibit the growth of Ps cepacia synergistically. In vitro combinations of other antibiotics have been shown to be synergistic against $P$ s cepacia. ${ }^{23-25}$ Synergy between three antibiotics (rifampicin, imipenem, and ciprofloxacin) has previously been demonstrated and therefore two or more antimicrobial agents may be needed..$^{25}$ Many patients with cystic fibrosis who are colonised with Ps cepacia also carry $P s$ aeruginosa and exacerbation may be caused by $P$ s aeruginosa with or without $H$ influenzae or Staph aureus. Our clinical experience would seem to indicate that combination chemotherapy results in in vivo activity against $P s$ cepacia despite resistance in vitro. Nottingham isolates of $P$ s cepacia are resistant to the aminoglycosides, azlocillin, ciprofloxacin, imipenem, aztreonam, and polymyxin B, but some are moderately sensitive to ceftazidime and most adult patients with cystic fibrosis show the same strain (unpublished observation).

We have considered several explanations for the clinical improvement of patients who were Ps cepacia positive despite in vitro antimicrobial resistance. Firstly, it is possible that in vitro antibiotic sensitivities do not reflect the in vivo situation within the lung due to the milieu of the inflammatory response. Alternatively the in vivo response may be due to synergism between antibiotics. Current methodology used in antibiotic susceptibility testing of Ps cepacia may be less appropriate for this organism which is slower growing than Ps aeruginosa and grows 
preferentially at $30^{\circ} \mathrm{C}$. It is also possible that a heavy growth of Ps cepacia may inhibit the recognition of other organisms such as Staph aureus and Haemophilus. Whilst this is a possibility it would not explain the results of treatment directed towards Ps aeruginosa in our study. An alternative explanation is that the response in both patient groups is due solely to effective physiotherapy which is causing improvement by enhancing sputum expectoration and reducing the inflammatory stimulus, thus reducing levels of inflammatory markers. This latter possibility would seem unlikely as previous studies have shown that intravenous antibiotics alone are more effective than physiotherapy alone at reducing $P s$ aeruginosa counts in sputum..$^{20}$ Antibiotics are also known to have other effects which may modify the response to infection including the release of endotoxin and the inhibition of the cytokine cascade. ${ }^{26}$ The possible immunomodulatory effect combined with some in vivo antibacterial activity, physiotherapy, and nutritional support may explain the clinical improvement. Consequently, beneficial effects might be explained despite persistence of the organism. Lastly, we considered whether the response to treatment in patients colonised with Ps cepacia may reflect treatment of $P s$ aeruginosa rather than $P s$ cepacia. For this reason we have compared the two subgroups of patients who were Ps cepacia positive (with and without Ps aeruginosa) and have found no differences in either lung function or inflammatory markers between patients colonised with Ps aeruginosa and Ps cepacia and those colonised with Ps cepacia alone. This suggests that treatment was as effective when only $P s$ cepacia was present. Alternatively, the clinical response to antibiotic treatment among patients who appeared to be colonised by Ps cepacia alone may simply reflect the treatment of underlying Ps aeruginosa as the inability to isolate this organism from the sputum does not exclude its presence within the lower respiratory tract.

The fact that we found that patients who were $P s$ cepacia positive responded well to antibiotics suggests that the reason for the greater decline in their lung function in some studies may be the result of lung damage occurring between antibiotic courses. ${ }^{6}$ It is interesting that our patients who were Ps cepacia positive required more courses of intravenous antibiotics over the previous 12 months than those patients who were Ps cepacia negative.

We conclude, therefore, that antibiotic treatment of patients who are $P s$ cepacia positive is often effective in vivo despite the multiresistant nature of this organism in vitro. Further work is required to determine the relation between in vitro sensitivity results and the response in vivo and the pattern of inflammatory response over a prolonged period in patients who are $P s$ cepacia positive. From a practical point of view anti- biotics should not be withheld from patients because of in vitro resistant patterns.

1 Simmonds EJ, Conway SP, Ghoneim ATM, Ross H, Littlewood JM. Pseudomonas cepacia: a new pathogen in patients with cystic fibrosis referred to a large centre in the United Kingdom. Arch Dis Child 1990;65:874-7.

2 Govan JRW, Brown PH, Maddison J, Doherty CJ, Nelson $\mathrm{JW}$, Dodd $\mathrm{M}$, et al. Evidence for transmission of Pseudomonas cepacia by social contact in cystic fibrosis. Lancet monas cepacia

3 Editorial. Pseudomonas cepacia - more than a harmless commensal? Lancet 1992;339:1385-6.

4 Lewin LO, Byard PJ, Davis PB. Effect of Pseudomona cepacia colonization on survival and pulmonary function of cystic fibrosis patients. $\mathcal{F}$ Clin Epidemiol 1990;43:125-31.

5 Tablan OC. Nosocomially acquired Pseudomonas cepacia infection in patients with cystic fibrosis. Infect Control Hosp Epidemiol 1993;14:124-6.

6 Muhdi KM, O'Hickey S, Smith G, Stableforth DE. Rate of decline of lung function in patients with cystic fibrosis colonised by Pseudomonas cepacia. Thorax 1993;48:1088.

7 Bhakta DR, Leader I, Jacobson R, Robinson-Dunn B, Honicky RE, Kumar A. Antibacterial properties of investigational, new, and commonly used antibiotics against isolates of Pseudomonas cepacia in Michigan. Chemotherapy 1992;38:319-23.

8 Rayner RJ, Wiseman MS, Cordon SM, Norman D, Hiller EJ, Shale DJ. Inflammatory markers in cystic fibrosis. Respir Med 1991;85:139-45.

9 Norman D, Elborn JS, Cordon SM, Rayner RJ, Wiseman MS, Shale DJ. Plasma tumour necrosis factor alpha in cystic fibrosis. Thorax 1991;46:91-5.

10 Valletta EA, Rigo A, Bonazzi L, Zanolla L, Mastella G. Módification of some markers of inflammation during treatment for acute respiratory exacerbation in cystic fibrosis. Acta Paediatr 1992;81:227-30.

11 Holt A, Brown D. Antimicrobial susceptibility. In: Hawkey PM, Lewis DA, eds. Medical bacteriology. A practical approach. Oxford: Oxford University Press, 1989:167-94.

12 Crouch SPM, Fletcher J. Effect of ingested pentoxifylline on neutrophil superoxide anion production. Infect Immun 1992;60:4504-9.

13 Meager A, Partis S, Leung H, Piel E, Mahon B. Preparation and characterisation of monoclonal antibodies directed against antigenic determinants of recombinant human tumour necrosis factor (rTNF). Hybridoma 1987;6:305-11.

14 Rocker GM, Wiseman MS, Pearson D, Shale DJ. Diagnostic criteria for adult respiratory distress syndrome: time for criteria for adult respiratory dis
reappraisal. Lancet $1989 ; \mathrm{i}: 120-3$.

15 Gilligan PH. Microbiology of airway disease in patients with cystic fibrosis. Clin Microbiol Rev 1991;4:35-51.

16 Goldmann DA, Klinger JD. Pseudomonas cepacia: biology, mechanisms of virulence, epidemiology. $\mathcal{F}$ Pediatr 1986 108:806-12.

17 Starke JR, Edweards MS, Langston C, Baker CV. A mouse model of chronic pulmonary infection with Pseudomonas aeruginosa and Pseudomonas cepacia. Pediatr Res 1987;22:698-702.

18 Tablan OC, Martone WJ, Doershuk CF, Stern RC, Thomassen MJ, Klinger JD, et al. Colonization of the respiratory tract with Pseudomonas cepacia in cystic fibrosis. Risk tory tract with Pseudomonas cepacia in cystic fibr

19 Hodson ME, Roberts CM, Butland RJA, Smith MJ, Batten JC. Oral ciprofloxacin compared with conventional intravenous treatment for Pseudomonas aeruginosa infection in adults with cystic fibrosis. Lancet 1987; i:235-7.

20 Regelmann WE, Elliott GR, Warwick WJ, Clawson CC. Reduction of sputum Pseudomonas aeruginosa density by antibiotics improves lung function in cystic fibrosis more than do bronchodilators and chest physiotherapy alone. than do bronchodilators and chest

21 Baynes RD, Bezwoda WR, Khan Q, Mansoor N. Relationship of plasma lactoferrin content to neutrophil regeneration and bone marrow infusion. Scand $\mathcal{f}$ Haematol 1986;36:79-84

22 Boxer LA, Smolen JE. Neutrophil granule constituents and their release in health and disease. Hematol Oncol Clin North Am 1988;2:101-20.

23 Kumar A, Wofford-McQueen R, Gordon RC. In vitro activity of multiple antimicrobial combinations against
Pseudomonas cepacia isolates. Chemotherapy 1989;35:24653.

24 Chin NX, Neu HC. Synergy of new C-3 substituted cephalosporins and tobramycin against Pseudomonas aeruginosa and Pseudomonas cepacia. Diagn Microbiol Infect Dis 1989;12:343-9.

25 Kumar A, Wofford-McQueen R, Gordon RC. Ciprofloxacin, imipenem and rifampicin: in-vitro synergy of two and three drug combinations against Pseudomonas cepacia. $\mathcal{f}$ three drug combinations against Pseudor

26 Simon DM, Koenig G, Trenhome GM. Differences in release of tumour necrosis factor from TPH-1 cells stimulated by filtration of antibiotic-killed Escherichia coli. $\mathcal{F}$ Infect Dis 1991;164:800-2. 